\title{
Adverse Selection Behavior in China's Pension Insurance Market for Urban and Rural Residents \\ SHEN Jiaxin ${ }^{1, a}$, ZHANG yechun ${ }^{2, b}$
}

1,2School of Business, Central South University, Hunan Changsha

a161611091@csu.edu.cn,b779838758@qq.com

Key Words: urban and rural residents' pension insurance; commercial pension insurance; adverse selection

\begin{abstract}
Using data from China Family Panel Studies(CFPS), the paper analyzes the adverse selection in urban and rural residents pension insurance, and its heterogeneity with different age income and level of education. We find the adverse selection is significant in the China's urban and rural social residents pension insurance, but is not significant in commercial pension insurance market .
\end{abstract}

\section{城乡居民养老保险的逆向选择行为 \\ 申嘉欣 ${ }^{1}$, 张也淳 ${ }^{2}$ \\ 1,2中南大学商学院, 长沙, 中国 \\ a161611091@csu.edu.cn,b779838758@qq.com}

关键字：城乡居民基本养老保险；商业养老保险；逆向选择

摘要：使用中国家庭追踪调查（CFPS）的调查数据, 分析了城乡居民养老保险市场的逆向选 择问题, 及其在不同年龄、不同收入和不同学历下的异质性。研究发现城乡居民基本养老保 险市场存在显著逆向选择现象，而商业养老保险市场逆向选择问题存在但并不显著。

\section{1.引言及文献回顾}

随着我国经济的快速发展和社会结构的加剧转型, 城乡居民的养老问题越来越突出。城 乡居民基本养老保险由个人或者家庭自愿选择是否参加，据保险经典文献（Rothschild et al， 1976）提出，在遵循同一的缴费条件和自愿参保的条件下，保险市场将会存在逆向选择问题。 而对我国养老保险市场逆向选择问题的研究主要是从理论分析层面指出了养老保险机制设计 的缺陷, 并提出改进。对城乡居民基本养老保险逆向选择进行实证研究的论文并不多。（赵建 国等，2013; 姚东旻等，2016; 江红莉等，2017)。

从现有研究来看, 国外研究证实了年金市场存在逆向选择（Friedman et al，1990)。还有 学者进一步分析是否参保、参保金额、参保年金类型与健康状态的关系, 结果显示都存在逆 向选择（Finkelstein et al, 2004; McCarthy et al, 2003; Finkelstein et al, 2006)。随后有学者 对不同保险市场逆向选择现象不一致的现象进行研究, 研究发现风险偏好是不同保险市场逆 向选择现象不一致的原因之一 (Cutler et al, 2008)。另外还有研究发现利智的年金市场存在 逆向选择 (Ruiz, 2014)。

国内对养老保险逆向选择问题进行实证研究的论文, 目前相对较少。有学者研究发现北 京市海淀区社会保险市场存在逆向选择现象 (张欢, 2006)。有研究发现在自愿选择参保档次 的情况下, 农民普遍选择最低档次的保费, 从而导致新行农村养老保险受到逆向选择的困扰 
(赵建国 等, 2013)。还有学者基于中国健康与养老追踪调查 2011 年的基线调查数据, 验证 新型农村养老保险市场是否存在逆向选择问题。(周否 等，2015）。

现有文献在研究养老保险市场主要使用的是自评指标, 但自评健康指标会受到风险偏好 和认知偏差的影响, 从而导致对自身健康的评价并不准确。针对以上问题, 本文使用中国家 庭追踪调查（CFPS） 2012 年以来的数据，对城乡居民基本养老保险市场逆向选择现象，以期 丰富和充实中国养老保险市场的逆向选择现象的相关研究。

\section{2.数据来源及描述性分析}

\section{(一) 数据来源}

本文的数据来源于北京大学中国社会科学调查中心实施的中国家庭追踪调查（CFPS）。 该调查从 2010 年开始开展访问，考虑到 CFPS 从 2012 年才开始调查新农保、城镇居民养老 保险以及城乡养老保险, 所以本文采用的样本为 2012 年、 2014 年和 2016 年的数据。本文还 删除了样本中 60 岁以上的样本 (国家规定 60 岁以上的老人不需要缴纳养老保险可直接领取 基础养老金）和参加城镇职工养老保险的样本，且删除了主要变量缺失的样本，最后得到城 乡居民基本养老保险 54287 个样本。

\section{（二）变量和描述性分析}

本文变量的定义和描述性统计如表 1 。

表 1 变量定义和描述性统计

\begin{tabular}{|c|c|c|c|c|}
\hline 变量名称 & 变量定义 & 观测值 & 均值 & 标准差 \\
\hline $\begin{array}{c}\text { 城乡居民基本养 } \\
\text { 老保险 }\end{array}$ & $\begin{array}{l}\text { 如果购买城镇居民养老保险、新型农村养 } \\
\text { 老保险中的一种, 该变量为 } 1 \text {, 否则为 } 0\end{array}$ & 54287 & 0.4798 & 0.4996 \\
\hline 商业养老保险 & $\begin{array}{l}\text { 如果购买商业养老保险, 该变量为 } 1 \text {, 否则 } \\
\text { 为 } 0\end{array}$ & 68835 & 0.0132 & 0.1140 \\
\hline 主观健康评价 & $\begin{array}{l}\text { 如果健康状况为非常健康、很健康或比较 } \\
\text { 健康, 该变量为 } 1 \text {, 否则为 } 0\end{array}$ & 91776 & 0.6672 & 0.4712 \\
\hline 客观健康评价 & $\begin{array}{l}\text { 如果调查员回答 “受访者健康状态” 的值 } \\
\text { 为 } 5-7 \text {, 该变量为 } 1 \text {, 否则为 } 0\end{array}$ & 86338 & 0.8028 & 0.3979 \\
\hline 最高学历 & $\begin{array}{l}\text { 文盲 }=1 \text { 小学 }=2 \text { 初中=3 高中=4 中专 }=5 \\
\text { 本科 }=6 \text { 硕士 }=7 \text { 博士 }=8\end{array}$ & 91776 & 2.3947 & 1.3623 \\
\hline 是否在婚 & $\begin{array}{l}\text { 如果婚姻状态为在婚, 该变量为 } 1 \text {, 否则为 } \\
0\end{array}$ & 91776 & 0.7923 & 0.4057 \\
\hline 医疗保险种数 & 参与医疗保险的种数 & 91776 & 0.9162 & 0.3462 \\
\hline $\begin{array}{l}\text { 家庭人均收入对 } \\
\text { 数 }\end{array}$ & $\ln ($ 家庭人均收入) & 91776 & 9.0251 & 1.2202 \\
\hline 性别 & 如果性别为男性, 该变量为 1 , 否则为 0 & 91776 & 0.4920 & 0.4999 \\
\hline 年龄 & 调查年份-出生年份 & 91776 & 45.8306 & 16.7545 \\
\hline 家庭规模 & 家庭成员人数 & 91776 & 4.2816 & 1.9659 \\
\hline 吸烟 & $\begin{array}{l}\text { 如果过去一个月吸过烟, 该变量为 } 1 \text {, 否则 } \\
\text { 为 } 0\end{array}$ & 91776 & 0.2852 & 0.4515 \\
\hline 喝酒 & $\begin{array}{l}\text { 如果过去一周内喝酒超过三次, 该变量为 } \\
1 \text {, 否则为 } 0\end{array}$ & 91776 & 0.1499 & 0.3571 \\
\hline 户口状态 & $\begin{array}{l}\text { 如果是农业户口, 该变量为 } 1 \text {,; 如果是非 } \\
\text { 农业户口, 该变量为 } 3\end{array}$ & 91776 & 1.5780 & 1.3884 \\
\hline 东部 & $\begin{array}{l}\text { 北京、天津、河北、辽宁、上海、江苏、 } \\
\text { 浙江、福建、山东、广东、海南 }\end{array}$ & 91776 & 0.4188 & 0.4934 \\
\hline 中部 & $\begin{array}{l}\text { 山西、吉林、黑龙江、安徽、江西、河南、 } \\
\text { 湖北、湖南 }\end{array}$ & 91776 & 0.3004 & 0.4584 \\
\hline 西部 & $\begin{array}{l}\text { 内蒙古、广西、重庆、四川、贵州、云南、 } \\
\text { 西藏、陕西、甘肃、青海、宁夏、新疆 }\end{array}$ & 91776 & 0.2604 & 0.4388 \\
\hline
\end{tabular}


资料来源：北京大学中国社会科学调查中心提供的CFPS数据, 下表同。

\section{3.实证方法和回归结果}

\section{（一）模型构建}

1.Probit 模型。由于本文使用的城乡居民基本养老保险和商业养老保险为虚拟变量，本文 使用固定效应的 Probit 模型, 来探讨健康风险与是否购买养老保险之间的关系及其异质性, 模型如下:

insurance $_{i}=\beta_{0}+\beta_{1}$ health $_{i j}+\beta_{i} X_{i}+\mu_{i}$

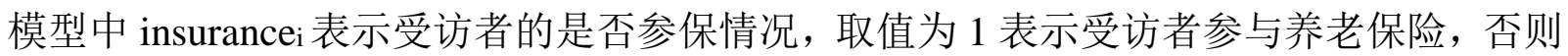
为 0 。 health $\mathrm{ij}_{\mathrm{ij}}$ 表示健康状态, 包括主观健康状态和客观健康状态两个方面, 二者相互补充以 增强结论的稳健性。 $X_{\mathrm{i}}$ 代表其他控制变量。

2.Bivariate Probit 模型。为了研究结果具有更稳健的估计结果, 本文进一步采用 Chiappori and Salanie(2000)的方法对逆向选择的检验进行了检验, 检验模型如下:

\section{health $h_{i j}=f\left(X_{i}\right)+\varepsilon_{i}$}

insurance $_{i}=f\left(X_{I}\right)+\lambda_{i}$

其中 health $\mathrm{ij}_{\mathrm{j}}$ 表示主观和客观健康状态, insurance $\mathrm{i}_{\mathrm{i}}$ 表是否购买养老保险, $\mathrm{X}_{\mathrm{i}}$ 则表示其他 的控制变量。

\section{（二）实证结果}

1. 城乡居民基本养老保险中的逆向选择。表 2 给出了主观健康评价和客观健康评价对是 否参加城乡居民基本养老保险决策影响的估计结果。结果显示主观健康评价好的人群参加城 乡居民基本养老保险的概率高且显著, 即城乡居民基本养老保险存在逆向选择。其中农村居 民中, 主观健康状态好的人群比普通人群参保概率高 $2.1 \%$, 而农村居民中, 主观健康评价好 的人群比普通人群参保概率高 $2.2 \%$; 客观健康评价好的农村居民参加城乡居民基本养老保险 的概率高且显著, 但城镇居民中客观健康评价与是否参加城乡居民基本养老保险无显著关系。

表2 城乡居民基本养老保险影响因素

\begin{tabular}{|c|c|c|c|c|}
\hline & \multicolumn{2}{|c|}{ 农村 } & \multicolumn{2}{|c|}{ 城镇 } \\
\hline \multirow[t]{2}{*}{ 主观健康评价 } & $0.0210^{* * *}$ & & $0.0221^{* *}$ & \\
\hline & $(0.0144)$ & & $(0.0306)$ & \\
\hline \multirow[t]{2}{*}{ 客观健康评价 } & & $0.0414^{* * *}$ & & 0.0136 \\
\hline & & $(0.0172)$ & & $(0.0426)$ \\
\hline \multirow[t]{2}{*}{ 学历 } & $0.0159^{* * *}$ & $0.0088^{* * *}$ & $-0.0324^{* * *}$ & $-0.0400^{* * *}$ \\
\hline & $(0.0049)$ & $(0.0066)$ & $(0.0105)$ & $(0.0107)$ \\
\hline \multirow[t]{2}{*}{ 是否在婚 } & $0.0791^{* * *}$ & $0.0762^{* * *}$ & 0.0174 & 0.0191 \\
\hline & $(0.0219)$ & $(0.0228)$ & $(0.0459)$ & $(0.0472)$ \\
\hline \multirow[t]{2}{*}{ 医疗保险种数 } & $0.3175^{* * *}$ & $0.3058^{* * *}$ & $0.1971^{* * *}$ & $0.1908^{* * *}$ \\
\hline & $(0.0252)$ & $(0.0265)$ & $(0.0326)$ & $(0.0329)$ \\
\hline \multirow[t]{2}{*}{ 家庭人均收入的对数 } & $0.0852^{* * *}$ & $0.0545^{* * *}$ & $-0.0729^{* * *}$ & $-0.0530^{* *}$ \\
\hline & $(0.0411)$ & $(0.0371)$ & $(0.0862)$ & $(0.0783)$ \\
\hline \multirow[t]{2}{*}{ 人均收入对数的平方 } & $-0.0047^{* * *}$ & $-0.0026^{* * *}$ & $0.0049^{* * *}$ & $0.0038^{* * *}$ \\
\hline & $(0.0025)$ & $(0.0023)$ & $(0.0048)$ & $(0.0045)$ \\
\hline \multirow[t]{2}{*}{ 性别 } & 0.0063 & 0.0073 & $-0.0172^{*}$ & -0.0137 \\
\hline & $(0.0167)$ & $(0.0173)$ & $(0.0342)$ & $(0.0349)$ \\
\hline \multirow[t]{2}{*}{ 年龄 } & $0.0364^{* * *}$ & $0.0350^{* * *}$ & $0.0374^{* * *}$ & $0.0344^{* * *}$ \\
\hline & $(0.0042)$ & $(0.0043)$ & $(0.0095)$ & $(0.0095)$ \\
\hline \multirow[t]{2}{*}{ （年龄/100）^2 } & $-3.6746^{* * *}$ & $-3.5836^{* * *}$ & $-4.3799^{* * *}$ & $-4.0794^{* * *}$ \\
\hline & $(0.5260)$ & $(0.5359)$ & $(1.1542)$ & (1.1629) \\
\hline 家庭规模 & 0.0010 & -0.0021 & $0.0150^{* * *}$ & $0.0142^{* * * *}$ \\
\hline
\end{tabular}




\begin{tabular}{ccccc} 
& $(0.0035)$ & $(0.0036)$ & $(0.0080)$ & $(0.0082)$ \\
吸烟 & 0.0095 & 0.0064 & -0.0150 & -0.0130 \\
& $(0.0192)$ & $(0.0198)$ & $(0.0414)$ & $(0.0420)$ \\
喝酒 & $-0.0253^{* * *}$ & $-0.0220^{* * *}$ & $-0.0260^{* *}$ & $-0.0278^{* *}$ \\
& $(0.0180)$ & $(0.0186)$ & $(0.0379)$ & $(0.0386)$ \\
\hline
\end{tabular}

注: 表中圆括号中的数字为稳健的标准误差，报告的系数均为probit模型的边际效应，下文均同。

2. 商业养老保险中的逆向选择。表3报告了是否购买商业养老保险与主观健康评价和客 观健康评价的关系, 结果显示城镇居民的逆向选择现象存在。对比城乡居民基本养老保险, 商业养老保险的逆向选择系数均显著低于同等条件下的城乡居民基本养老保险的系数, 这是 由于商业养老保险将部分风险高的人群通过核保排除在外, 而城乡居民基本养老保险市是政 府提供的, 并不会像商业养老保险公司那样根据被保险人的风险不同而分类，所以商业养老 保险中逆向选择现象相对较弱。

表3 商业养老保险参保的影响因素

\begin{tabular}{|c|c|c|c|c|}
\hline & \multicolumn{2}{|c|}{ 农村 } & \multicolumn{2}{|c|}{ 城镇 } \\
\hline \multirow[t]{2}{*}{ 主观健康评价 } & 0.0011 & & $0.0031^{*}$ & \\
\hline & $(0.0389)$ & & $(0.0536)$ & \\
\hline \multirow[t]{2}{*}{ 客观健康评价 } & & 0.0005 & & $0.0086^{*}$ \\
\hline & & $(0.0483)$ & & $(0.0801)$ \\
\hline \multirow[t]{2}{*}{ 学历 } & $0.0022^{* * * *}$ & 0.0021 & $0.0010^{* * * *}$ & $0.0041^{* * * *}$ \\
\hline & $(0.0164)$ & $(0.0173)$ & $(0.0178)$ & $(0.0182)$ \\
\hline \multirow[t]{2}{*}{ 是否在婚 } & -0.0007 & -0.0009 & 0.0043 & 0.0038 \\
\hline & $(0.0576)$ & $(0.0612)$ & $(0.0749)$ & $(0.0782)$ \\
\hline \multirow[t]{2}{*}{ 医疗保险种数 } & $0.0039^{* *}$ & 0.0038 & $0.0032^{*}$ & 0.0045 \\
\hline & $(0.0693)$ & $(0.0764)$ & $(0.0559)$ & $(0.0582)$ \\
\hline \multirow[t]{2}{*}{ 家庭人均收入的对数 } & $-0.0091^{* * *}$ & -0.0071 & 0.0063 & -0.0039 \\
\hline & $(0.0778)$ & $(0.0571)$ & $(0.1100)$ & $(0.0964)$ \\
\hline \multirow[t]{2}{*}{ 人均收入对数的平方 } & $0.0007^{* * *}$ & 0.0006 & $0.0003^{* *}$ & 0.0004 \\
\hline & $(0.0045)$ & $(0.0034)$ & $(0.0060)$ & $(0.0055)$ \\
\hline \multirow[t]{2}{*}{ 性别 } & -0.0004 & -0.0007 & 0.0033 & -0.0034 \\
\hline & $(0.0450)$ & $(0.0477)$ & $(0.0584)$ & $(0.0602)$ \\
\hline \multirow[t]{2}{*}{ 年龄 } & $0.0019^{* * *}$ & 0.0019 & $0.0008^{* * * *}$ & $0.0039^{* * * *}$ \\
\hline & $(0.0100)$ & $(0.0104)$ & $(0.0136)$ & $(0.0141)$ \\
\hline \multirow[t]{2}{*}{ (年龄/100)^2 } & $-0.2282^{* * *}$ & -0.2186 & $0.0885^{* * *}$ & $-0.4684^{* * *}$ \\
\hline & (1.1650) & (1.1983) & $(1.5313)$ & $(1.5756)$ \\
\hline \multirow[t]{2}{*}{ 家庭规模 } & -0.0003 & -0.0004 & 0.0008 & 0.0009 \\
\hline & $(0.0094)$ & $(0.0102)$ & $(0.0141)$ & $(0.0146)$ \\
\hline \multirow[t]{2}{*}{ 吸烟 } & 0.0008 & 0.0014 & 0.0042 & -0.0004 \\
\hline & $(0.0479)$ & $(0.0497)$ & $(0.0728)$ & $(0.0752)$ \\
\hline \multirow[t]{2}{*}{ 喝酒 } & 0.0001 & -0.0002 & 0.0037 & -0.0039 \\
\hline & $(0.0472)$ & $(0.0502)$ & $(0.0649)$ & $(0.0672)$ \\
\hline
\end{tabular}

3. Bivariate Probit模型。从表4可以看出，城乡居民基本养老保险中，逆向选择的确存在。 而商业养老保险中, 自评健康好和客观健康好的人的相关系数均为正, 表明商业养老保险中 也存在逆向选择。城镇居民在城乡居民基本养老保险和商业养老保险中自评健康好的相关系 数显著大于农村居民，说明城镇居民逆向选择的程度大于农村居民。 
表4 参保与健康状态的相关性: Bivariate Probit模型估计

\begin{tabular}{|c|c|c|c|c|}
\hline & \multicolumn{4}{|c|}{ 城乡居民基本养老保险 } \\
\hline & \multicolumn{2}{|c|}{ 农村 } & \multicolumn{2}{|c|}{ 城镇 } \\
\hline & 自评健康 & 客观健康 & 自评健康好 & 客观健康好 \\
\hline \multirow[t]{2}{*}{$P($ rho) } & $0.0335^{* * *}$ & $0.0620^{* * *}$ & $0.0445^{* *}$ & 0.0242 \\
\hline & $(0.0086)$ & $(0.0097)$ & $(0.0181)$ & $(0.0228)$ \\
\hline \multirow[t]{2}{*}{ 样本量 } & 43147 & 40395 & 11074 & 10755 \\
\hline & & 民民商业养 & & \\
\hline \multirow[t]{2}{*}{$\mathrm{P}$ (rho) } & 0.0260 & 0.0171 & $0.0618^{* *}$ & $0.0793^{*}$ \\
\hline & $(0.0232)$ & $(0.0270)$ & (0.0313) & $(0.0413)$ \\
\hline 样本量 & 54072 & 50880 & 14696 & 14086 \\
\hline
\end{tabular}

\section{4.结束语}

本文利用中国家庭跟踪调查（CFPS）2012年以来的数据，从主观和客观健康两个方面研 究了健康状态与是否参加养老保险的关系。本研究发现在城乡居民基本养老保险中, 无论是 农村居民还是城镇居民都在存在显著逆向选择，而商业养老保险仅城镇居民存在显著的逆向 选择，且城乡居民基本养老保险的逆向选择现象较商业养老保险更为严重。由于城乡居民基 本养老保险和商业养老保险对家庭养老有较好的替代作用, 所以政府应该进一步推进和完善 城乡居民基本养老保险和商业养老保险, 并增强城乡居民基本养老保险缴费对保险待遇的激 励，以减弱城乡居民社会居民养老保险的再分配作用导致的逆向选择问题。

\section{References}

[1] Rothschild M, Stiglitz J. Equilibrium in Competitive Insurance Markets: An Essay on the Economics of Imperfect Information[J]. Quarterly Journal of Economics, 1978. 90(4):629-649.

[2] ZHAO Jianguo ,HAI Long. Dilemma of"Adverse Selection”And Financial Subsidy Incentive Mechanism Design of New Rural Social Pension Insurance [J]. Issues in Agricultural Economy, 2013. (9):77-84.

[3] YAO Dongmin,LI Jiasheng. Convergence or Divergence - The Optimal Contractual Design of Chinese Pension Scheme [J]. Modern Economic Science, 2016.38(3):1-12.

[4] Jiang Hongli,He Jianmin,Yao Hongxing. The Research on How to Governance the Premium Evasion Phenomenon in the Process of Social Security Fund Raising Based on Evolutionary Game [J]. Statistics \& Decision, 2017. (4):161-163.

[5] Friedman B M, Warshawsky M J. The Cost of Annuities: Implications for Saving Behavior and Bequests[J]. Quarterly Journal of Economics, 1990. 105(1):135-154.

[6] Finkelstein A, Poterba J. Adverse Selection in Insurance Markets: Policyholder Evidence from the U.K. Annuity Market[J]. Journal of Political Economy, 2004.112(1):183-208.

[7] Mccarthy D, Mitchell OS. International Adverse Selection in Life Insurance and Annuities[J]. Nber Working Papers, 2003. 8:119-135.

[8] Finkelstein, A. and J. Poterba. Testing for Adverse Selection with Unused Observables[J], Working Paper, 2006. No.12112

[9] Cutler D M, Finkelstein A, Mcgarry K. Preference Heterogeneity and Insurance Markets: Explaining a Puzzle of Insurance.[J]. American Economic Review, 2008. 98(2):157 
[10]Ruiz J L. Annuity Choices in Chile: A Dynamic Approach[J]. Emerging Markets Finance \& Trade, 2014. 50(sup5):6-21.

[11] Zhou L, Jiang B, Wang J. The Analysis of Adverse Selection in New Rural Social Pension Insurance[J]. Insurance Studies, 2015. 